\title{
Prevalence of Urinary Incontinence among Young Healthy Females in Gujarat - A Cross Sectional Study
}

\author{
Vinal Charpot ${ }^{1}$, Vaishali Sagar ${ }^{2}$ \\ ${ }^{1}$ Lecturer/Physiotherapist, Government Physiotherapy College, Civil Hospital, Ahmadabad, Gujarat \\ ${ }^{2}$ Tutor/Physiotherapist, Government Physiotherapy College, Civil Hospital Ahmadabad, Gujarat
}

Corresponding Author: Vinal Charpot

\begin{abstract}
Background: Urinary incontinence is a problem that creates both physical and psychological nuisance to all women. It has significant impact on socioeconomically aspect of life too. This problem needs to be studied in detail in young Gujarati population because of lack of precise data at early age. It is also essential to estimate the disease burden that will help in to find out preventive strategies and early intervention. Hence, the present study has been carried out to determine the prevalence of urinary incontinence among young healthy Gujarati females.

Methods: This was a cross sectional study conducted among 323 young female aged between 18 to 45 years from month of December 2017 to October 2018. All the data was collected by Proforma consisting of socio demographic details, QUID questionnaire for female urinary incontinence diagnosis and also questions to assess the severity of urinary incontinence. Incontinence was classified as urge, stress and mixed based on symptoms according to QUID questionnaire.

Results: The prevalence of UI was $29.36 \%$ (323 out of 1100). Of the total female having incontinence, highest numbers were found to have stress incontinence $(51.70 \%, 167 / 323)$ followed by mixed $(37.15 \%, 120 / 323)$ and urge incontinence $(11.15 \%, 36 / 323)$. Out of 323 subjects $214(66.25 \%)$ were young healthy females aged between 18 to 35 years having complained of urine leakage. Majority $(55.60 \%)$ were suffering from stress urinary incontinence in young age.

Conclusion: Urinary incontinence is bothersome condition among all young females too. Awareness has to be created about the any kind of urine leakage at any age.

So that necessary steps can be taken to prevent and to treat this silent disease at early age.
\end{abstract}

Key wards: Prevention, urinary incontinence (UI), young females, QUID questionnaire

\section{INTRODUCTION}

Urinary incontinence is a severe debilitating condition affecting all women causing significant impact on the physical, psychological and socio-economical aspects of life. It is one of the most significant and prevalent condition. ${ }^{1}$

Many studies have been proven that prevalence of UI is very common in middle and old aged women ${ }^{2}$

So it is necessary to find out prevalence of UI is affecting young aged healthy females too.
The prevalence ranges from $8-45 \%$ in various studies across the world. In 2008, a total of 250 million women from developing countries of Asia were affected with urinary incontinence and this is expected to increased by 303 million by 2018. , $^{2,8}$

According to previous study has been done by Agrawal BK, Agrawal N, et al found that prevalence, risk factors, impact on quality of life and treatment seeking behavior among middle aged women. ${ }^{3}$ 
In this study aim is to find out prevalence of urinary incontinence in young women because due to young age a, discomfort, shame and loss of self confidence this silent problem has been under report.

Women's health plays important role in determining the health of future generation because it has an intergenerational issue. There are many ways which make women's health deferent from men. Although women have a longer life span as compares to men, they need more doctor visits, more disability days, higher rates of illness, and greater use of health services. The paradox is a result of various factors that affect our health services including our lifestyle. ${ }^{4}$

Very little attention is paid to gynecological problems in non-pregnant women and problem such as UI is never discussed or even considered as a health issue. It is essential to focus on the quality of life affected by UI as it is preventive in nature.

UI is involuntary leakage of urine resulting due to pelvic floor dysfunction and strongly associated with the female gender. The prevalence of UI in India is also quite high and ranges from $10 \%$ in rural areas to $34 \%$ in urban areas. ${ }^{5}$

The data by Dionko et al, who showed that only $40 \%$ of incontinence patients would actually bring the issue of incontinence to the attention of their physicians. ${ }^{6}$

Very less community based studies are available from our state on prevalence of urinary incontinence and its severity affecting the quality of life in young female. This study can help in find out of prevalence of UI and then very much beneficial in to formulating the preventive strategies and early intervention in young age of female. Hence, this present study has been carried out to determine the prevalence of UI and among young female in Ahmadabad, Gujarat.

While taking history screening females with UI in physiotherapy department, it has been found that many of them young girls were not even comfortable to talk about urine leakage even though they were belongs to medical profession because of shame and they start hiding this as it will be cure without doing anything. Later on their quality of life will be affected and further socioeconomically problems will arise.

Uma Singh and Brijit Bishwas, reported that prevalence of urinary in continence is common in middle and old aged women (50 or more than 50 years old) 7,8

In this study by doing this talk regarding UI it will increase awareness in young healthy female.

Here, there is a strong need to know about prevalence of UI in young healthy females, so that we could definitely prevent further consequence in future regarding UI in young age.

\section{AIMS AND OBJECTIVES}

The main aim of the study is to find out prevalence of urinary incontinence in young healthy female in Gujarat

\section{Objectives:}

1. To find out prevalence of UI in young healthy females.

2. To find out prevalence of different types of UI in young healthy females

3. To increase awareness about UI in young healthy females at early age.

\section{METHODOLOGY}

Study design: Cross sectional study

Study period: 11 month from December 2017 to October2018.

Study area: Physiotherapy college and government spine institute Civil hospital, Asarwa. Ahmadabad (Gujarat)

\section{Inclusion criteria}

Inclusion criteria were all young healthy females in age group 18 to 45 years giving consent for the study. 
Vinal Charpot et.al. Prevalence of urinary incontinence among young healthy females in Gujarat - a cross sectional study.

\section{Exclusion criteria}

Pregnant women

Neurological disorders

Psychological disorders

\section{Sample size:}

Out of 1100 women, 323(29.36\%) were enumerated.

A cross sectional study was conducted with all females that include all young healthy students and staff at physiotherapy department, civil hospital in December 2017 to October 2018.

Among 1100 women, all eligible women in the age group 18-45 years were included for this study.

After explained about the purpose of study and QUID questionnaire to all participants, the questionnaire was given to them. As almost all participants were educated the questionnaires were filled by themselves.

During history taking of all subjects it has been found that compared to age between 35 to 45 year old females, all young females between 18 to 35 years $(66.25 \%)$ they were having more sedentary life style and not doing any physical exercises. $^{24}$

BMI and life style also a risk factor for urine leakage in young females.

\section{Data collection}

A demographic detail includes name, age, sex, education, occupation and marital status of the study participants. Table 1

In this study there was use of QUID questionnaire. $^{9}$

It is a validated tool to diagnose the type of urinary incontinence. It consist of a six questions were used to diagnosing stress, urge and mixed incontinence in female. Table 2

\section{QUID QUESTIONNAIRE ${ }^{10}$}

The Questionnaire for female Urinary Incontinence Diagnosis.

\begin{tabular}{|c|c|c|c|c|c|c|}
\hline $\begin{array}{l}\text { Do you leak urine (even small drops), wet yourself, or wet } \\
\text { your pads or undergarments... }\end{array}$ & $\begin{array}{l}\text { None of } \\
\text { the time }\end{array}$ & Rarely & $\begin{array}{l}\text { Once in a } \\
\text { while }\end{array}$ & Often & $\begin{array}{l}\text { Most of } \\
\text { the time }\end{array}$ & $\begin{array}{l}\text { All of } \\
\text { the time }\end{array}$ \\
\hline 1. when you cough or sneeze? & $\square$ & $\square$ & $\square$ & $\square$ & $\square$ & $\square$ \\
\hline 2. when you bend down or lift something up? & $\square$ & $\square$ & $\square$ & $\square$ & $\square$ & $\square$ \\
\hline 3. when you walk quickly, jog or exercise? & $\square$ & $\square$ & $\square$ & $\square$ & $\square$ & $\square$ \\
\hline 4. while you are undressing in order to use the toilet? & $\square$ & $\square$ & $\square$ & $\square$ & $\square$ & $\square$ \\
\hline $\begin{array}{l}\text { 5. Do you get such a strong and uncomfortable need to urinate } \\
\text { that you leak urine (even small drops) or wet yourself before } \\
\text { reaching the toilet? }\end{array}$ & $\square$ & $\square$ & $\square$ & $\square$ & $\square$ & $\square$ \\
\hline $\begin{array}{l}\text { 6. Do you have to rush to the bathroom because you get a } \\
\text { sudden, strong need to urinate? }\end{array}$ & $\square$ & $\square$ & $\square$ & $\square$ & $\square$ & $\square$ \\
\hline
\end{tabular}

\section{Scoring:}

Each item scores 0 (None of the time), 1 (Rarely), 2 (Once in a while), 3 (Often), 4 (Most of the time) or 5 (All of the time). Responses to items 1, 2 and 3 are summed for the Stress score; and responses to items 4,5 , and 6 are summed for the Urge score.

\section{RESULTS}

Out of 1100 subjects, $323(29.36 \%)$ participants were completed this study.

In this cross sectional study the data shown that prevalence of urinary incontinence in healthy young females was $29.36 \%$. Out of 1100 females 323 females were reported with complain of abnormal urine leakage. Table 1

According to this study data shown that not only middle or old aged females had complain of urinary incontinence but young healthy females also had this problem. Table 2

Out of 323 women 167 had stress UI. Among them $71.85 \%$ of women were young healthy females.

In young healthy female age between 18-25 years, $50.85 \%$ had stress, 9.16\% had urge and $40 \%$ had mixed type of urinary incontinence. Table 3

The data obtained is shown in following tables. 
Vinal Charpot et.al. Prevalence of urinary incontinence among young healthy females in Gujarat - a cross sectional study.

Table 1: Demographic details of study participants. $(n=323)$

\begin{tabular}{|l|l|l|l|}
\hline Characteristics & & Frequency $(\mathbf{N})$ & Percentage $(\%)$ \\
\hline Age & $18-25$ years & 120 & 37.15 \\
& 25-35 years & 94 & 29.10 \\
& 35-45 years & 109 & 33.74 \\
\hline Marital status & Single & 120 & 37.15 \\
& Married & 203 & 62.84 \\
\hline Education & Higher secondary & 111 & 34.36 \\
& Graduate & 212 & 65.63 \\
\hline Occupation & Skilled & 212 & 65.63 \\
& Semiskilled & 111 & 34.36 \\
\hline
\end{tabular}

Table 2: Distribution of study population of urinary incontinence type. (n=323)according to quide questionnaire

\begin{tabular}{|l|l|l|}
\hline Type of UI & FREQUENCY(N) & PERCENTAGE (\%) \\
\hline STRESS INCONTINENCE & 167 & 51.70 \\
\hline URGE INCONTINENCE & 36 & 11.15 \\
\hline MIXED INCONTINENCE & 120 & 37.15 \\
\hline TOTAL & 323 & \\
\hline
\end{tabular}

Table 3: prevelence of urinary incontinence accoerind to different age criteria
\begin{tabular}{|l|l|l|l|}
\hline AGE(YEARS) & NO OF SUBJECTS & TYPE OF UI & PERCENTAGE (\%) \\
\hline $18-25$ & 120 & STRESS-61 & 50.83 \\
& & URGE-11 & 9.16 \\
& & MIXED-48 & 40.00 \\
\hline $25-35$ & 94 & STRESS-58 & 61.70 \\
& & URGE- 06 & 6.38 \\
& & MIXED-30 & 31.91 \\
\hline $35-45$ & 109 & STRESS-47 & 43.11 \\
& & URGE-19 & 17.43 \\
& & MIXED-43 & 39.44 \\
\hline TOTAL & 323 & & \\
\hline
\end{tabular}

In this study it was shown that young aged women also companied about urine leakage. They are equally being suffered from this silent problem.

\section{DISCUSSION}

In this cross sectional study, urinary incontinence diagnosed by QUID questionnaire ${ }^{10}$ which is based on answers to leading questions about symptoms of urinary incontinence.

This study provides an opportunity to analyze the prevalence and determinants of different types of urinary incontinence in a large series of young females using standard methods for recording symptoms.

QUID questionnaire was directly filled by subjects under the supervision by therapist, so it will increases the reliability of diagnosis of various type of urinary incontinence without being under report due to shame and hesitance.

Out of 1100 females, 323 females reported urinary incontinence and prevalence was $29.36 \%$ in young females. This findings is almost similar to studies done in Pondicherry and west Bengal which reported a prevalence of $34.1 \%$ and $21.7 \%$ respectively. ${ }^{11,12}$ but few studies done in India reported low prevalence rate .studies done by Bodhare et al in Andhra Pradesh and by Agrawal et al in Uttar Pradesh reported a prevalence of $10 \%$ and $12 \%$ respectively. 13,14 this variation in prevalence may due to difference in survey method, sample size difference in definition used in the study and duration of study.

Other studies using the same definition on similar population, prevalence was $25-45 \%$. ${ }^{13,14}$

Other various studies also using same population but different type of leakage reported a prevalence of $30-37 \%$ 15,16

In our study, the prevalence of stress, mixed and urge type was $51.70 \%$, $37.15 \%$ and $11.15 \%$, respectively. This was similar to most of the other studies in which stress urinary in continence was commonest type. ${ }^{17,18}$

Even though most of the studied has been reported that significant high prevalence of urinary incontinence in women above 40 years, according to Hagglund ${ }^{15}$, Middleton and Nemir they had proven that young females (18-30 
years) also reported with significant prevalence of urinary in continence.

In this study, prevalence of urinary incontinence in young females (18-25 years) was $37.15 \%$ which is strongly agree with Neimr and Middleton who was reported $52 \%{ }^{15}$ and $51 \%$ reported by Wolin studied among college students. ${ }^{20}$

Sina almouse, Alda Bandin Avn Loon et al reported that prevalence of urinary incontinence among young naulliparous adolescent and middle aged women ranged from $1 \%$ to $42.2 \%$ and those with UI of any sort, the prevalence of SUI ranges from $12.5 \%$ to $79 \% .{ }^{21,22}$

Their aim was to systematically review studies investigation the prevalence of UI in naulliparous adolescent and middle aged women and to provide an overview of risk factors associated with UI.

In this study it has found that majority of young females $(71.85 \%)$ with UI were sedentary life style. According to this risk factor this is similar to the finding by Aniulience et al. ${ }^{23}$

Another study done by Liu et al in china found that UI was common among women who lack physical exercise. ${ }^{24}$

\section{STRENGTHS}

It was one of the fewer studies in young population of a developing country like India where data relating to urinary incontinence are scarce. Taking into consideration cultural taboo and embarrassment associated with urinary incontinence, a hospital based study in this topic is more feasible alternative than community based in which maintenance of privacy during data collection is difficult.

\section{LIMITATION}

- All data were self reported by study participants. It can lead to bias data.

- We were included only young healthy females so this study cannot be extrapolated to other cultures and are not generalize to all age group.

- Definitive testing was not done to measure urinary incontinence.
In this study about majority of females were suffering from stress incontinence $(51.39 \%)$, mixed $(37.46 \%)$ and urge incontinence $(11.14 \%)$. These findings show that most of them were young healthy females and they had tolerated this problem. This might be due to embarrassment and shyness at young age to talk about urine leakage. So that awareness has to be created among young females about this condition and importance of getting treated at young age to prevent further medical and psychological morbidity.

\section{CONCLUSION}

Urinary incontinence is a significant health problem in community. With the help of simple questionnaire, burden of this problem can be estimated in young healthy female at early age.

This cross sectional study had proven that healthy young females also had complained of urine leakage.

The prevalence of urinary incontinence was found to be $71.85 \%$ of women were young and healthy Their Age between $18-25$ years, $50.85 \%$ had stress, $9.16 \%$ had urge and $40 \%$ had mixed type of urinary incontinence.

This study will be helpful to all young healthy females to be aware about urinary incontinence.

Knowing about prevalence of urinary incontinence is very important, so that necessary preventive measures and treatment can be taken in early age.

\section{ACKNOWLEDGEMENT}

The authors are thankful to Dr Minal Bhavasr and all respected staff members of government Physiotherapy College for their support in this study and also very much grateful to all participants for their kind interest throughout this study.

\section{Conflict of Interest: None}

\section{Source of Funding: None}




\section{Ethical Consideration:}

Institutional ethical clearance was obtained before commencing the study.

The all participants were explained about the purpose of this study and informed consent was obtained.

\section{REFERENCES}

1. Komelilifar rm javadifar np .afshari pm, haghighizade MHM honaramandpour AM,the prevelence,subtypes and obstretric risk factors of urinary incontinence in reproductive age women referred to community health care centre ,Iran -2015 .Int $\mathrm{j}$ community based nurs midwifery. 2017;593);275-283

2. Agrawal bk, agrawal n. urinary incontinence :prevalence ,risk factors, impact on quality of life and treatment seeking ,behavior among middle aged women int surg $\mathrm{j}$ $.2027 ; 4(4): 1953$

3. V.S. self -reported urinary incontinence and factors associated with symtom severity in community dwelling adult women:implications for womens health promotion. Bmc womens health.2013 13:16.

4. Singh U ,agrawal $p$, verma ML, Dalela D, singh N,Sankhwar P.prevelence and risk factors of urinary incontinence in Indian women. Ahospital based survey.indian $\mathbf{J}$ Urol 2013;29:31-6

5. Gentry jh .womens health : acourse of action social factors affecting womens health .public health reports supplement. Available from https://webache .googleusercontent.com(Last accessed 2020 march 01)

6. Diokno Ananias c. incidence and prevalence of stress urinary incontinence. adv stud med 2003:4(8E): S824-8p.

7. Singh U, Agarwal P, Verma ML, Dalela D, Singh N, Shankhwar P. Prevalence and risk factors of urinary incontinence in Indian women: A hospital-based survey. Indian $\mathbf{J}$ Urol. 2013 Jan;29(1):31-6. doi: 10.4103/0970-1591.109981. PMID: 23671362 ; PMCID: PMC3649597.

8. Brijit biswas .Arita bhattacharya .urinary incontinence, its risk factors and quality of life: A study among women aged 50 years and above in rural health facility of west Bengal. J. Midlife health ,2017 jul sept,8(3):130-136
9. Am J obstet. Validity of utility measures for women with urge,stress and mixed urinary incontinence. Gynecol ,2014.jan 210(1):85

10. Farrell, sa ,bent a ,amir- khalkhali b ,rittenberg D, Zilbert A. women's ability to assess their urinary incontinence type using the QUID as an educational tool.int urogynecol 2013,may ,24(5):759-62

11. Mangla $\mathrm{m}$, single d. gestational gigantomastia: a systemic review of case reports. J midlife health. 2017;8(4):40-4

12. Poomalar gk,priyadharshini m. Prevalence of urinary incontinence in reproductive women and its impact on quality of life. Int $\mathrm{j}$ reprod contraception obstet gynecol.2015: 4(5): $1353-8$

13. Agrawal Bk, Agrawal N .urinary incontinence: Prevalence ,Risk Factors,Impact On Quality Of Life And Treatment Seeking Behavior Among Middle Aged Women.Int Surg J.2017;4(6):1953

14. Bodhare T, Valsangkar S, Bele S. An Epidemiological Study Of Urinary Incontinence And Its Impact On Quality Of Life Among Women Aged 35 Years And Above Ina Rural Area.Indian J Urol.2010;26(3):353

15. Hagglund d, Olsson h ,leppert j. urinary incontinence : an unexpected large problem among young females. Results from a population -based study. Fam pract.1999:16:506-9.(pubmed)

16. Yarnell jw,voyel gj, Richards co , Stephenson tp . the prevalence and severity of urinary incontinence in women's epidemiology community health. 1981: 35 : 71-4(PMC free article)(Pub med)(Google Scholar)

17. Samuelssion b, victor a,tibblin g. a population based study of urinary incontinence and nocturia among 20-59 years .prevelence, well-being and wish for treatment . acta obstest gynecol scand. 1997;76: 74-80(Pubmed)(Google Scholar)

18. Kinchen Ks ,Burgio K ,Dionko Ac,Obenchain R. Factors Associated With Wommens Decisions To Seek Treatment For Urinary Incontinence . J Womens Health . 2003;12:687-98 (Pubmed)(Google Scholar)

19. Sommer $\mathrm{p}$, bauer $\mathrm{t}$, neilsen kk, Hermann $\mathrm{gg}$ steven $\mathrm{k}$, et al. voiding patterns and prevalence of incontinence in women a questionnaire survey . br j , uro .1990;66:125.(pubmed)(google scholar) 
Vinal Charpot et.al. Prevalence of urinary incontinence among young healthy females in Gujarat - a cross sectional study.

20. Neimir a, middleton rp .stress incontinence in young nulliparous women : a statistical study.am obstet gynecol.1954;68:1166-8. (Pubmed)(Google Scholar)

21. Wolin lh. Stress incontinence in young ,healthy nulliparous female subjects. J urol. 1969;101:545-9. (Pubmed)(Google Scholar)

22. Saniya almousa, alda bandin van loon.prevalence aof UI in naulliparous adolescent and middle aged women and to provide an overview of risk factors associated with UI. A systemic review volume 107,2018,p.g 78-83

23. Aniulience R, Aniulis P, Steiblinence V. Risk Factors And Types Of Urinary Incontinence Among Middle Aged And
Opder Male Female Primary Care Patients In Kaunas Region Of Lithuania: Cross Sectional Study.Urol J .2016;13(1):2552-61

24. Liu B, Wang L, Huang S-S, Wu Q,Wu D-L . Prevalence And Risk Factors Of Urinary Incontinence Among Chinese Women In Shanghai. Int J chin Exp Med .2014; 7:68696

How to cite this article: Charpot V, Sagar V. Prevalence of urinary incontinence among young healthy females in Gujarat - a cross sectional study. Int J Health Sci Res. 2021; 11(6):100-106. DOI: https://doi.org/10.52403/ ijhsr.20210614 